\title{
LUDICA EN LA JUGADA
}

\section{Iván Arturo Torres*}

Este texto hace parte del sistema de capacitación y asesoría a organizaciones juveniles, diseñado por el Programa Presidencial de Juventud, Mujer y Familia; la Fundación Restrepo Barco; la Fundación para la Educación Superior, el Instituto Fes de Liderazgo Juvenil y COLJUVENTUD.

Se trata de interpelar los imaginarios más cercanos a la vivencia juvenil acerca del deporte y la recreación, los recorre con un ánimo desprevenido, escenifica diferentes posiciones que acerca de ellos circulan entre los jóvenes, $y$, finalmente, asume una posición frente a la lúdica y su pedagogización, mostrando cómo en su interior subyacen lógicas que deben ser develadas e interpretadas.

El hilo conductor del texto, al igual que el del conjunto del sistema de capacitación en el cual está inscrito, es el reconocimiento del Otro, y por consiguiente, del conflicto como generador de lo social. En este marco, el análisis apunta a mostrar un conjunto de experiencias simbólicas y prácticas vinculadas a un mundo de vida de los jóvenes: el deporte y la recreación, los cuales se asumen como uno de los escenarios de su vida cotidiana. A partir de allí, surgen los personajes y los libretos.

"En la Jugada" no se presentan fórmulas mágicas para resolver el asunto del deporte y la recreación, tal como se expresa hoy. Sin embargo, las líneas centrales del análisis convergen en una propuesta abierta, que debe ser examinada, debatida no sólo en los círculos académicos. Se trata de una propuesta de la cual se pueden apropiar los jóvenes colombianos que están asumiendo ya la construcción de nuevas experiencias de la cotidianeidad. Antes de entrar en el texto, un cuento que contribuye a la contextualización.

\section{Cuento}

Al llegar a su casa, Pinocho vio un enorme y viejo grillo, el que le habló acerca de la importancia de la escuela y la necesidad de concentrarse en los estudios. Pinocho no lo escuchó.

Huyó de su casa y, luego, en una nueva alcoba, trató de cocinar algo; sin embargo, la comida se le quemó.

Semanas más tarde, regresó a su casa y decidió que estudiaría. Un día, rumbo a la escuela, divisó un grupo de muchachos que cantaban y reían. Se preguntó: ¿A dónde ir pues?

Más tarde salió a pasear y se encontró con una gran cantidad de extraños sujetos. A poco y sin darse cuenta se quedó sin una sola moneda.

En otra ocasión, y buscando una mejor oportunidad, llegó al pueblo de las Abejas Industriosas. ¡Allí, todos trabajaban y trabajaban y trabajaban! El ocio y el placer ¡no existían! ¿Será que yo tengo un lugar en ese pueblo? Preguntó Pinocho con dudas.

\footnotetext{
* Licenciado en Educación Física, profesor del Opto de EF. de la U.P.N. 
Otro día Pinocho prometió a un hada que se ajuiciaría y que se dedicaría a fondo al estudio... Sin embargo... Al otro día...

Finalmente se animó, fue a la escuela y el maestro estuvo feliz con él, ya que Pinocho era el primero que llegaba, el último que salía, siempre estaba sentado y no decía nada.

Así que se transformó en un alumno brillante. Por esto, algunos compañeros lo invitaron a conocer al "Gran Tragamares", para distraerlo y que no fuera a la escuela. Su profesor y otros compañeros se preocuparon por su ausencia.

Otro día, aceptó la invitación de su amigo Pabilo y se fugaron de sus casas. La idea era ir al "País de los Juguetes", donde se divertirían todo el tiempo.

Al llegar al "País de los Juguetes", Pinocho dijo a Pabilo:

No entiendo nada.. ¿por qué el estudio, el juego y el trabajo están en lugares distintos? ¿No hay un lugar donde simultáneamente estén los tres?

Y este cuento ¿cómo termina? y ¿cómo se llama?

\section{CRONICA DE UN TROPEL ANUNCIADO}

"El verano ya está aquí, el tiempo para pelear en las calles es correcto" M. Jagger - K. Richard - Street Fighting Man.

Nosotros generalmente jugamos en las noches o los fines de semana hacemos la vaca para comprar el balón y nos fajamos severos partidos... con toda la finura del caso... al mejor estilo del "Pibe". Casi nunca hay complique... bueno... a no ser que juguemos en algún campeonato. Ahí si la cosa cambia... cuando de competir se trata, jle probamos al que sea que somos los mejores!

En cierta ocasión... organizaron en el barrio un campeonato de microfútbol. El premio para el campeón era un televisor a color. Como era de esperarse... el combo de la cuadra se inscribió: Pacho, Mario, el Loco, Oso, Carlos M, el Chiqui, Russi, Jet'e tula, el Negro y Luis que es el más juicioso... el único que entrena y juega en varios equipos.

Llegamos a la final. Nos tocó jugar contra los manes de Aguas Claras. Éramos conocidos y hasta bien llaves con algunos de ellos... pero final es final: ¡tremendo bombo el que se armó! Ellos se trajeron todo su combo y nosotros el nuestro. Cada barra a un lado de la cancha y cuando uno pasaba por ahí. ..tremenda mano de madrazos que le echaban: ¡Vé mico... partile las patas a ese mechudo que es el que nos está haciendo el daño! y al otro lado: vamos mijo no se deje dar... ¡métasela también que usted no está sólo y aquí hay quien lo respalde! En fin... la vaina se fue calentando.

Les empacamos el primero como a los diez minutos del segundo tiempo...tremendo riflazo del loco. ..casi mata al chino que les estaba tapando. De pronto hubo una jugaba enredada... dos manes que ruedan por el piso... patada que va y patada que viene. Nos empataron el partido.. pero el árbitro anuló el gol y, ¡hay comenzó la rumba!... ¡tremenda faena! 
Se meten las barras a la cancha y como un ejercito inundan todo. Eso boliaban patadas, puños, garrotazos, botellazos, etc... ¡Que desorden tan tenaz! Un tipo gordo de saco rojo y pantalón gris le metió al Mario tremendo bailado.. qué piedra que nos dio... es que ese chino es calmado y es bien con todos Nosotros. El Aníbal se metió a defenderlo y estaba dándole al gordo cuando otro man le pega tremendo varillazo y fue a esconderse en un carro. Nosotros lo encendimos a piedra... ¡casi acabamos con ese loco!

En esas estábamos... de pronto... fui a parar de cara en el suelo. Vi una mancha borrosa y sentí severo golpe en la cabeza. ¡ Un tipo flaco con cara de pescado me había metido un garrotazo ni el berraco!

Al momento ... un pelado que yo no conocía cayó junto a mi. Luego.. .aparecieron otros dos... uno pateó al mancito en las costillas. Yo escuché el impacto de los zapatos contra el cuerpo del pelado y l'olvieron a llover patadas cada vez con más fuerza. Surgió otro man y luego otro... ¡Ya eran como seis los que golpeaban al pelado! No sé quién llamó al CAI...vi venir un policía y de repente... ¡todo el mundo desapareció!... El parque quedó vacío... como si nada hubiera pasado... Yo me fui para la casa todo golpeado. ..casi no me podía mover. Todo sucedió tan rápido que no podría explicar en qué momento pasaron tantas cosas. Llamé a Carlos M., que es el más calmado de todo el combo para saber cómo estaba. A él también le habían dado quedamos de vernos al otro día.

Entonces qué viejo man?... ¡todo bien o qué! Saludé a Carlos M., cuando lo vi venir cojeando.

-Ahí vamos mijo. ..un poco adolorido todavía.

Fuimos a la tienda de Jóse a tomarnos una gaseosa y hablar sobre el partido y el tropel. Allí nos encontramos con Russi, Chiqui y el Negro.

-Oiga hermano... a la final, ¿por qué se armó la pelea anoche?... es que yo llegué en lo mejor del cuento y el ambiente estaba tan propio que no me enteré cual era el motivo de tremendo concierto...

-Pues, ¿por qué iba a ser? lo mismo de siempre... iporque a esos manes no les gusta perder! y como los teníamos entrados al baile... jdecidieron armar la fiesta!...contestó rápidamente Russi.

-Pero... ¿Por qué será tan importante ganar o perder?... ¿no será posible disfrutar del juego sin preocuparse solamente por eso y sin tener que acabar con todo el mundo.

-¡Me extraña Carlos M...volvió a decir Russi... usted sabe que uno compite es para ganar... para quedar campeón... de eso se trata, o si no, ¿qué gracia tendría jugar?... ijugar por jugar no vale la pena!... usted sabe que ese cuentico de que lo importante es competir y no ganar es para perdedores... para manes mediocres... ¿sí o qué?

-Pero es que los locos de Aguas Claras son amigos de nosotros... ¿acaso eso no importa?

-¡Ah!..jyo no sé!... A la final, en el barrio siempre hemos jugado así. Todos sabemos cómo es el asunto y de esta forma nos divertimos. 
-iQué va hermano!... volvió a decir Carlos M. iqué diversión ni que nada!... ¿por qué no le pregunta al pelado que patearon anoche si él se estaba divirtiendo?... ¿usted cree que el Aníbal después de tremendo varillazo estaba muy contento?...¿ ¿acaso cuando de divertimos se trata los demás no cuentan?... entonces.. ¿podemos pasar por encima de los demás con tal de sentirnos bien?... y, ¿qué sucede cuando otros se divierten con nosotros?

-¡Me extraña viejo Carlos que venga a salirme con esas cosas!... usted sabe que los tropeles en los campeonatos son normales... eso siempre pasa... no ve que ¿final sin tropel no es final? No entiendo por qué se aterra de algo que es natural.

- Yo no sé ... anotó Carlos M...¿acaso porque algunos campeonatos terminan en tropeles es natural que eso suceda?... ¿acaso no somos nosotros los que hacemos que las cosas sucedan de una forma o de otra'? yo no creo que esto suceda porque sí y que así tenga que ser necesario.

- ¿Sabe qué Carlitos?... para mí que a usted le están haciendo daño los golpes que le dieron ayer y por eso le dió a la pensadera... usted sabe que nosotros jugamos es para probar que somos los mejores y por eso somos reconocidos por aquí... todo el mundo sabe que el combo de la cuadra no hay quien le aguante.. .eso es lo más importante y ahí no hay nada que pensar

... ¡mejor nos vemos después!

- Listo viejo Russi... de todas formas, ipiénselo!

- ¡Nos vemos Carlos M!

- Hablamos luego Russi!

\section{CHARLA CON LOS PROTAGONISTAS (Primera escena)}

Bien, aquí nos encontramos frente a una forma particular de asumir el deporte. Seguramente esta escena que acabamos de ver ya ha sido vista o vivida por ustedes en alguna ocasión. Es frecuente que los campeonatos que se organizan en muchos de nuestros barrios terminen en severos tropeles. podríamos decir que lo no frecuente es que esto no suceda. Pero... ¿por qué es asumido así el deporte? ¿Qué es lo que está en juego durante un partido? ¿Qué es lo que lleva a que, tanto los jugadores como los espectadores puedan comportarse tan violentamente?

"Hasta que los leones tengan sus propios historiadores, las historias de cacerías seguirán glorificando al cazador", dice un proverbio africano. Por eso, la mejor forma de aclararnos estos interrogantes y poder entender lo que aquí acontece es hablar con sus propios protagonistas. Les propongo, entonces, que llamemos a algunos de ellos para que conversemos unos instantes.

EL AUTOR: Bueno viejo Russi, cuando uno se pone a mirar la forma en que ustedes practican el deporte, surgen una cantidad de cuestiones difíciles de entender... por ejemplo, desde su punto de vista ¿Qué explica todos esos excesos que rodean sus encuentros deportivos? 
RUSSI: Yo creo que más que excesos son accesos. El deporte es un medio de romper el aislamiento en que uno está, es una forma de hacerse oír, de llamar la atención y ser reconocidos.

EL AUTOR: Pero, normalmente, ustedes van preparados para pelear, escomo si no les interesara el juego mismo. ¿Qué es lo que realmente está en juego en un "encuentro" deportivo?

RUSSI: Lo que uno se juega en un partido es su imagen. Como se trata de competir hay que imponerse sobre los demás. Ser campeón, tener la valla menos vencida, quedar como goleador, ser el más ágil, el más fuerte, etc. Esto, ¿No hace que uno deje de ser anónimo? ¿que sea reconocido?

EL AUTOR: Digamos que esto permite entender un poco el comportamiento de los jugadores; pero mirando el tropel que se armó el otro día, ahí aparece otro personaje: los espectadores. Pensándolo bien no son tan espectadores sino que se vuelven actores. ¿Qué es lo que sucede con estos? ¿Cómo podemos explicar su protagonismo?

RUSSI: Yo creo que es básicamente el mismo asunto del que veníamos hablando: sólo que quienes están en la barra no buscan un protagonismo directo sino que lo hacen por identificación. ¿Qué quiere decir esto? Que en la barra uno se identifica con los jugadores de su equipo, que de otra parte son sus amigos o familiares, y siente como propios los triunfos y las derrotas de éstos. Claro que, como se juega es para ganar, ¿no es válido que la barra también haga lo que esté a su alcance para que su equipo quede campeón? ¿para influir en el resultado?

EL AUTOR: Si analizamos otra vez el partido del otro día, uno se encuentra con una cantidad de acciones violentas. Claudia... en tu opinión ¿qué explicaría tanta violencia?

CLAUDIA: En realidad yo estoy sorprendida con todo esto...claro que para nosotras, el Cuento con el deporte es distinto... los hombres tienen generalmente más posibilidades de hacer deporte que uno... los del tropel son ellos. Nosotras tenemos contacto con otras manifestaciones deportivas y no hay mayores problemas.

LUIS: Claro que mirando el campeonato de micro femenino que organizaron en el barrio me he dado cuenta que ahí parece no haber mucha diferencia...

RUSSI: Yo creo que la raíz de esto es evidente. Si nos fijamos bien, en el deporte, como en la vida misma, ¿no pasa que uno está en continua competencia? ¿En un enfrentamiento constante? De otra parte, todos sabemos que el campeón es uno sólo, que los puestos de privilegio, los que dan reconocimiento, son pocos y hay que pelear por ellos. Así que uno se pregunta: ¿para triunfar todo está permitido? Por ejemplo, hace unos días vi en la televisión a un boxeador que durante una pelea le pegó severo mordisco al otro. Al final lo entrevistaron y el hombre dijo textualmente "en el deporte todo está permitido. lo importante es no dejarse pillar" ¿,Entonces yo pienso si ahí está la respuesta a todo esto?

EL AUTOR: Finalmente la conversación nos lleva a considerar otro aspecto: el de las reglas del juego. Coincidimos en que, tanto en el deporte como en la vida cotidiana, estamos en continua competencia con otros. Claro que, según se nos ha dicho, en el deporte esta competencia se efectúa en el marco de unas reglas que todos aceptamos voluntariamente y que por ello, se trata de una competencia regulada. Dentro de esta 
visión, la violencia aparece no por la competencia misma sino por no respetar las reglas del juego. ¿Cuál es su opinión al respecto?

RUSSI: Yo creo que el deporte refleja de una u otra manera la forma en que transcurre la cotidianeidad de una sociedad. En cierta ocasión escuché a Francisco Maturana, el entrenador de la Selección Colombia, decir que "uno juega como vive". De acuerdo con esto, la forma en que nosotros practicamos el deporte, la manera de asumir la competencia deportiva, no es sino el reflejo de lo que tenemos que hacer para lograr sobresalir y ser alguien en nuestra vida cotidiana. Vivimos en un medio social, en el cual, para alcanzar el éxito se utiliza la zancadilla, el codazo, el empujón, el soborno o la imposición; estas son las reglas del juego. ¿Por qué esperar, entonces, que en el deporte se compita en otra forma?

EL AUTOR: Bueno, aquí volvemos a un problema bien de fondo. Es verdad que tanto en la vida diaria como en el deporte la violencia está presente. Pero por eso mismo nos tenemos que preguntar ¿Por qué? 